\title{
Stilbene derivatives from melinjo extract have antioxidant and immune modulatory effects in healthy individuals
}

\author{
J. Luis Espinoza*1, Dao Thi An ${ }^{1}$, Ly Quoc Trung ${ }^{1}$, Kayoko Yamada ${ }^{1}$, Shinji Nakao ${ }^{1}$ and Akiyoshi Takami ${ }^{1,2}$ \\ ${ }^{1}$ Department of Hematology Oncology, Kanazawa University Hospital, Kanazawa University, Kanazawa, Japan Takara machi 13-1, Kanazawa, 920-8641, Japan \\ ${ }^{2}$ Department of Internal Medicine, Division of Hematology, Aichi Medical University, School of Medicine, Nagakute, Aichi, Japan
}

\begin{abstract}
The ethanol extract of Melinjo seeds (MSE), an edible fruit native to Southeast Asia, is rich in resveratrol dimer (gnetin C) and other stilbenes. In preclinical studies MES was shown to exert antioxidant, anti-inflammatory and other health promoting activities. This study evaluated the cellular and molecular immune responses in 5 healthy volunteers at baseline and after the oral administration of MSE for 28 days. The administration of MES resulted in a significant increase in the antioxidant activity of the plasma and a decrease in the protein carbonyl content of the plasma compared with the corresponding baseline levels. The circulating numbers of $\mathrm{B}$ and T lymphocytes remained essentially unchanged throughout the course of the study, however MES consumption was associated with an increase in the proportion of circulating NK cells and regulatory T cells (CD3+, CD4+, CD25, CD127low/neg). In addition, MES-treated peripheral blood mononuclear cells more efficiently generated Treg cells in vitro compared with their un-treated counterparts. These findings demonstrate that MES modulates oxidative stress parameters in the plasma of healthy individuals and has biological effects on immune cells.
\end{abstract}

\section{Introduction}

Ethanol extracts from the seeds of the melinjo (Gnetum gnemon L.), a perennial tree native to Southeast Asia, was recently discovered to contain several stilbenoids, including trans-resveratrol (resveratrol monomer), gnetin $\mathrm{C}$ (resveratrol dimer), gnetin $\mathrm{L}$, gnemonoside $\mathrm{A}$, gnemonoside $\mathrm{C}$ and gnemonoside $\mathrm{D}$. In a seminal report, these melinjo derivatives, referred to as "melinjo extract" (MES), were reported to possess free radical scavenging activity, as well as antimicrobial effects against food-contaminating microorganisms and enterobacteria [1]. In subsequent studies, MES showed a strong inhibitory effect in a murine model of tumor angiogenesis [2] and modulated cytokine production in cultured Peyer's patch cells from mice [3]. Since melinjo leaves, fruits and seeds are frequently consumed as part of the Indonesian cuisine [1], it was anticipated that MES should be safe for humans [1]. Consistent with this notion, high doses of MSE powder $5,000 \mathrm{mg}$ daily) were well tolerated in healthy individuals [4]. In addition, in a randomized controlled study in non-obese Japanese males, Konno and colleagues reported that MES consumption (750 mg daily for eight weeks), was safe and associated with a significant decrease in serum uric acid levels, as well as an increase in the plasma levels of HDL [5]. Moreover, a recent toxicological study reported no signs of toxicity in rats exposed to extremely high concentrations $(1,000 \mathrm{mg} / \mathrm{kg} /$ day $)$ of MES [6].

Because MES contains a resveratrol monomer and resveratrol dimer and these agents have been reported to possess several health promoting properties, including anti aging effects $[7,8]$, cancer chemopreventive potential $[2,8,9]$ and immune modulatory effects in several preclinical studies $[3,10]$, we investigated the potential health promoting effects of the repeated administration of MES in healthy volunteers using measurable changes in circulating immune cells and the modulation of oxidative stress parameters in the plasma and urine samples as biomarkers. Our data revealed that MES induced biological effects on circulating immune cells and showed considerable antioxidant activities in vivo.

\section{Materials and methods}

\section{Study design}

Five healthy volunteer ( 3 males, 2 females; $34-46$ years old, median 42 years old; $50-76 \mathrm{~kg}$, median $63 \mathrm{~kg} ; 160-184 \mathrm{~cm}$, median $167 \mathrm{~cm}$; body mass index [BMI], $19-28 \mathrm{~kg} / \mathrm{m}^{-2}$, median $21 \mathrm{~kg} / \mathrm{m}^{-2}$ ) were enrolled in this phase 1 trial (UMIN-CTR \#UMIN000007690), which was approved by the Kanazawa University Hospital Institutional Review Board and conducted in accordance with the Declaration of Helsinki. All subjects provided their written informed consent prior to enrollment. Inclusion criteria included no subjective symptom of any disease, having normal liver and renal function, no history of consumption of phytochemical supplement or vitamins one month before enrollment into this study, and the willingness to abstain from the ingestion of resveratrolcontaining food and drink during the course of the study. Exclusion criteria were chronic medications and diseases, previous history of invasive cancer within 5 years, previous history of non-invasive cancer within a year, and previous history of smoking within a year.

The enrolled subjects were given tablets containing MES (LOT\#

Correspondence to: J. Luis Espinoza, MD, PhD, Department of Hematology Oncology, Kanazawa University Hospital, Kanazawa University, Kanazawa, Japan Takara machi 13-1, Kanazawa, 920-8641, Japan, Tel: 8176265 22274; Fax: 8176234 4277; E-mail: luis@staff.kanazawa-u.ac.jp

Key words: melinjo seed extract, resveratrol dimer, Gnetin C, Tlymphocytes, peripheral blood mononuclear cells, oxidative stress

Received: October 14, 2015; Accepted: November 02, 2015; Published: November 05, 2015 
0801K) (Hosoda SHC, Fukui, Japan). The subjects were instructed to ingest 20 MES tablets every morning for 28 consecutive days and were evaluated on a weekly basis for compliance and adverse events according to the National Cancer Institute Common Terminology Criteria for Adverse Events (CTCAE) version 4.0 [11]. Each MES tablet contained $38.5 \%$ MES powder, $49.5 \%$ cyclodextrin, $10 \%$ polysaccharide as a thickener and $2 \%$ of sucrose. The MES powder contained the following stilbenes: gnemonoside A (1.14\%), resveratrol monomer or trans-resveratrol $(0.09 \%)$, gnemonoside $\mathrm{D}(1.54 \%)$ and gnetin C, $(2.57 \%)$. The primary objective of this trial was to evaluate the safety of MES and to investigate the antioxidant effects of MES in vivo. The secondary objective was to assess the effects of MES on circulating lymphocytes as measured by the expression of surface receptors on specific lymphocytic subsets.

\section{Sample preparation}

Blood samples were collected at pre-dose (day 0) and at 14, 28, 42 and 56 days after starting MES consumption. The blood was collected in $7 \mathrm{ml}$ heparinized collection tubes. From each sample, two $\mathrm{ml}$ of blood were centrifuged under refrigeration $(10 \mathrm{~min}, 1300 \times \mathrm{g}$ ). To prevent light damage of MES stilbenes and their metabolites, the plasma was transferred to LightSafe $1.5 \mathrm{ml}$ centrifuge tubes (SigmaAldrich, St. Louis, MO, USA) and stored at $-70^{\circ} \mathrm{C}$ until use. Peripheral blood mononuclear cells (PBMCs) were isolated using gradient centrifugation from the remaining $5 \mathrm{ml}$ of blood. Isolated PBMCs were immediately analyzed by flow cytometry for their expression of cell surface markers or were cryopreserved for further use.

\section{Pharmacokinetic evaluations}

A high performance liquid chromatography (HPLC) analysis for the quantification of MES stilbenes was performed using the Acquity UPLC System (Waters Corp., Milford, MA USA) as described previously $[4,12]$. The metabolites were separated at $40^{\circ} \mathrm{C}$ using a reversed phase column (Acquity UPLC BEH C18, $2.1 \times 100 \mathrm{~mm}, 1.7 \mu \mathrm{m}$ ). Injections were carried out with an autosampler maintained at $20^{\circ} \mathrm{C}$. The mobile phase comprised water and acetonitrile and was pumped at a flow rate of $0.3 \mathrm{ml} / \mathrm{min}$. Tandem mass spectrometry (MS/MS) was performed on a $\mathrm{Q}$-Premier XE triple quadrupole mass spectrometer (Waters) equipped with a turbo electrospray ion source (ESI) in the positive and negative mode and a heated curtain gas interface to the high-vacuum region of the mass analyzer. Mass detection and quantification of analysis were accomplished in multiple reaction monitoring (MRM) mode and spectra analyzed using the MassLynx software program (Waters). The quantification of trans-resveratrol, gnetin C, gnetin C monoglucuronide, gnemonoside $\mathrm{A}$, gnemonoside $\mathrm{D}$ was performed using the plasma matrix standard curve. The limits of detection (LOD) and limits of quantitation (QOD) were determined as the analyte concentration that gave a signal-to-noise ratio $(\mathrm{S} / \mathrm{N})$ of 3 and 10 , respectively. cis-gnetin $\mathrm{C}$ was confirmed using gnetin $\mathrm{C}$ solutions irradiated with artificial UV light for $0.5 \mathrm{~h}$.

\section{Measurement of plasma antioxidant capacity}

The total antioxidant capacity of the plasma was measured with a metmyoglobin assay using an Antioxidant Assay Kit (Cayman, Ann Arbor, MI, USA). The assay relies on the ability of antioxidants of a given sample to inhibit the oxidation of ABTS (2,2'-azinobis [3-ethylbenzothiazoline 6-sulfonate]) to $\mathrm{ABTS}^{+}$by metmyoglobin. The amount of $\mathrm{ABTS}^{+}$was monitored colorimetrically at $405 \mathrm{~nm}$. The antioxidant capacity of the plasma to prevent $\mathrm{ABTS}^{+}$formation was compared with that of Trolox and was quantified as millimolar
Trolox equivalent. All measurements were carried out on the same day and were performed using a Multiskan microplate reader (Thermo Labsystems, Beverly, MA, USA). The fold change was calculated by dividing the value from the experimental group by the value from the control group (baseline or W0). To convert expression ratio values less than 1.0 to fold changes, the formula $-1 /$ ratio was used. For example, $-(1 / 0.259)=-3.861$.

\section{Measurement of carbonylated proteins in plasma}

The carbonyl content in plasma proteins was quantified using a colorimetric Protein Carbonyl Assay Kit following the manufacturer's protocol (Cayman). This assay utilizes the generation of hydrazone that occurs as a result of the reaction between 2,4-dinitrophenylhydrazine (DNPH) and protein carbonyls found in the samples. The amount of protein-hydrazone was quantified by comparing the absorbance at 280 $\mathrm{nm}$ to a standard bovine serum albumin curve.

\section{Flow cytometry}

Freshly isolated PBMCs were stained with antibodies specific to the cell surface markers of T cells, B cells and NK lymphocytes lineage, including anti-CD3, CD16, anti-CD19, CD56, (BD Biosciences, San Jose, CA, USA), anti-NKG2D, anti-NKp30 anti-NKp46, anti-DNAM-1 (R\&D Systems, Minneapolis, MN, USA), anti-NKG2A, and anti$\gamma \delta$ TCR (BD Bioscience). The cells were also stained with NIR zombie dye (BioLegend, San Diego, CA, USA) to exclude dead cells from the analysis. The stained cells were analyzed in a BD Canto instrument (BD Biosciences). The proportion of circulating regulatory $\mathrm{T}$ cells (cTreg) was assessed in cryopreserved PBMCs stained with anti-CD3, antiCD4, anti-CD25 anti-CD127 and NIR zombie dye. Flow cytometry data were analyzed using the FlowJo software package (Tree Star) and data was expressed as the percentage of positive cells or as the mean fluorescent intensity.

\section{Measurement of urinary 8-Oxo-2'-deoxyguanosine (8- OHdG)}

Urine samples from the participants were collected in sterile tubes at baseline and two and four weeks after MES administration. Samples were kept refrigerated and shipped to the Japan Institute for the Control of Aging (JaICA), Nikken Sail Co. Ltd. (Fukuroi, Shizuoka, Japan) where the urinary levels of 8-OHdG, adjusted by the creatinine concentration correction method, were determined.

\section{Cell culture}

PBMCs from healthy individuals were seeded onto 24-wells plates $\left(1 \mathrm{X} 10^{6}\right.$ cells $\left./ \mathrm{ml}\right)$ and cultured for four days in RPMI medium supplemented with $20 \%$ FBS and $100 \mathrm{IU} / \mathrm{ml}$ of recombinant IL-2, 10 $\mathrm{ng} / \mathrm{ml}$ of recombinant IL-15 (PeproTech, Rocky Hill, NJ, USA) and anti-CD3/CD28 magnetic beads (Invitrogen, Waltham, MA, USA) in the presence or the absence of several concentrations of MES (solubilized in DMSO), pure gnetin C (Hosoda), pure resveratrol (Sigma-Aldrich) or vehicle (0.5\% DMSO). The cells were then stained with fluorochrome-labeled anti-CD3, anti-CD25, anti-CD4, and antiCD127 antibodies and analyzed by flow cytometry.

\section{ELISA}

PBMCs from three healthy individuals were seeded onto 24-wells plates $\left(1 \times 10^{6}\right.$ cells $\left./ \mathrm{ml}\right)$ and cultured for 48 hours in RPMI medium supplemented with $20 \%$ FBS and $100 \mathrm{IU} / \mathrm{ml}$ of recombinant IL-2 in the presence or absence of several concentrations of MES. In some experiments, PBMCs were primed with $2.5 \mu \mathrm{g} / \mathrm{ml}$ of 
phytohemagglutinin A (PHA) for 24 hours and then cultured for other 48 hours in RPMI medium supplemented with 20\% FBS and recombinant IL-2 in the presence or absence of several concentrations of MES. Culture supernatants were collected and the levels of interferon gamma (IFN- $\gamma$ ), tumor necrosis factor alpha (TNF- $\alpha$ ) and granzyme B (GZMB) were assessed using specific ELISA kits, following the manufacturer's recommendations (Mabtech, Nacka Strand, Sweden). To measure the plasma levels of GZMB, samples were diluted in a ready-to-use ELISA diluent (catalog \#3652-D2, Mabtech, Cincinnati, $\mathrm{OH}, \mathrm{USA}$ ) and then assessed using the GZMB ELISA kit.

\section{Statistical analysis}

All data are reported as the means \pm standard deviations. When comparisons were made between two different groups, statistical significance was determined using Student's $t$-test. The statistical significance of multiple comparisons was determined using a oneway analysis of variance. The data were considered to be statistically significant when the $P$ value was $\leq 0.05$.

\section{Results}

\section{Safety and pharmacokinetic evaluations}

All five subjects enrolled in this study received MES tablets for 28 consecutive days, which was equivalent to $262 \mathrm{mg}$ of gnetin $\mathrm{C}$ and $5.8 \mathrm{mg}$ of trans-resveratrol daily. Among the volunteer participants, one subject experienced grade 1 diarrhea that resolved without sequelae or intervention. No other adverse events were reported. Since comprehensive pharmacokinetics studies of the single dose and repeated administration of MES in Japanese healthy volunteers have been reported elsewhere [4,5], in this study we did not perform repeated measurements of MES stilbenes and its metabolites and instead measured the concentrations of trans-resveratrol, gnetin $\mathrm{C}$ or their metabolites at baseline and two weeks after MES administration. A HPLC analysis of the plasma samples collected at two weeks after the consumption of MES revealed the presence of trans-resveratrol $(0.0612 \pm 0.0535 \mu \mathrm{g} / \mathrm{ml})$, gnetin $\mathrm{C}(0.344 \pm 0.205 \mu \mathrm{g} / \mathrm{ml})$ and gnetin $\mathrm{C}$ monoglucoronide $(0.09664 \pm 0.0561 \mu \mathrm{g} / \mathrm{ml})$. Conversely, MES stilbenes or their metabolites were not detected in any of the plasma samples collected at baseline (Table 1).

\section{Effects of MES on the plasma antioxidant capacity}

Using an assay that measures the total antioxidant activity of the plasma, including any endogenous and antioxidant activities that could be derived from MES consumption, we measured the plasma antioxidant capacity at baseline and two and four weeks after consumption. Consistent with its reported antioxidant and scavenger activities, the intake of MES correlated with a significant increase in the overall antioxidant capacity in the plasma samples. By the second week after MES intake, the plasma antioxidant capacity was nearly 2 -fold higher than that of the samples collected at baseline, reached a 2.5 -fold increase by week 4 and returned to baseline levels in the samples collected at 8 weeks after MES intake (Figure 1A). In addition, compared with the baseline levels, a significant decrease $(\mathrm{p}=0.001)$ in the carbonyl protein content in the plasma samples was detectable by 2 weeks after MES consumption. The carbonyl protein content returned to the baseline levels at week 8 of the study (Figure 1B).

Because endogenous DNA damage plays a major role in mutagenesis, carcinogenesis and aging, and MES showed strong antioxidant potential, we next tested the effects of MES on the levels of 8-OHdG, which is a broadly used biomarker of endogenous DNA damage [13]. Compared to the levels of $8-\mathrm{OHdG}$ in urine samples collected at baseline, in samples collected 2 weeks after MES intake the urinary 8-OHdG levels decreased in four of the five participating subjects (Figure 1C).

\section{Effects of MES on circulating immune cells}

A flow cytometry analysis of PBMCs isolated from blood samples collected at baseline and every two weeks revealed that at week four after MES administration, the percentage of circulating $\mathrm{CD}^{+} 6^{+}$ $\mathrm{NKG}_{2} \mathrm{D}^{+} \mathrm{NK}$ cells was significantly higher than at baseline (Figure $2 \mathrm{~A}$ ). The percentage of $\mathrm{CD}^{+} \mathrm{T}$ cells, $\mathrm{CD} 19^{+} \mathrm{B}$ cells and $\gamma \delta^{+} \mathrm{T}$ cells remained essentially unchanged during the course of the study (Figure 2B).

\section{Effects of MES on surface immune receptors}

A cell surface analysis of selected activator and inhibitory markers on NK cells showed that, compared to the baseline levels, a modest but significant increase in the expression of the activator receptor NKG2D on circulating NK cells was associated with MES intake (Figure 3A). Conversely, other NK surface receptors, including NKp46 (Figure 3B), CD16 (Figure 3C), DNAM-1 (Figure 3D) and NKG2A (Figure 3E) remained essentially unchanged.

\section{Effects of MES on circulating regulatory $T$ cells}

In a previous study resveratrol, which is one of the components of MES, was reported to promote the proliferation of circulating regulatory $\mathrm{T}$ cells in mice [14]. To determine whether MES modulates Treg cells in humans, we determine the proportion of circulating Treg cells at baseline and at various time points after two MES administrations. Circulating Treg cells were characterized by the expression of CD4 and CD25 and the low or lack of expression of CD127 [15]. At week two after MES intake, the percentage of circulating Treg increased in all five individuals, although this was not a significant increase compared with the Treg numbers at baseline; however, at week four after MES administration, the percentage of circulating Treg cells was significantly

Table 1. Stilbene derivatives in the plasma of healthy individuals before and two weeks after MES intake.

\begin{tabular}{|c|c|c|c|c|c|c|}
\hline \multirow[t]{2}{*}{ Donor \# } & \multicolumn{2}{|c|}{ trans-resveratrol $(\mu \mathrm{g} / \mathrm{ml})$} & \multicolumn{2}{|c|}{ Gnetin-C $(\mu \mathrm{g} / \mathrm{ml})$} & \multirow{2}{*}{\multicolumn{2}{|c|}{$\begin{array}{c}\text { Gnetin-C }(\mu \mathrm{g} / \mathrm{ml})(\text { monoglucoronide }) \\
\text { week } 0 \text { week } 2\end{array}$}} \\
\hline & week 0 & week 2 & weel & week 2 & & \\
\hline 1 & 0 & 0.0254 & 0 & 0.267 & 0 & 0.0784 \\
\hline 2 & 0 & 0.0879 & 0 & 0.149 & 0 & 0.0419 \\
\hline 3 & 0 & 0.143 & 0 & 0.467 & 0 & 0.153 \\
\hline 4 & 0 & 0.172 & 0 & 0.197 & 0 & 0.0496 \\
\hline 5 & 0 & 0.0323 & 0 & 0.640 & 0 & 0.159 \\
\hline Average & \multicolumn{2}{|c|}{$0.0621 \pm 0.0535$} & \multicolumn{2}{|c|}{$0.344 \pm 0.205$} & \multicolumn{2}{|c|}{$0.0964 \pm 0.05$} \\
\hline
\end{tabular}


A

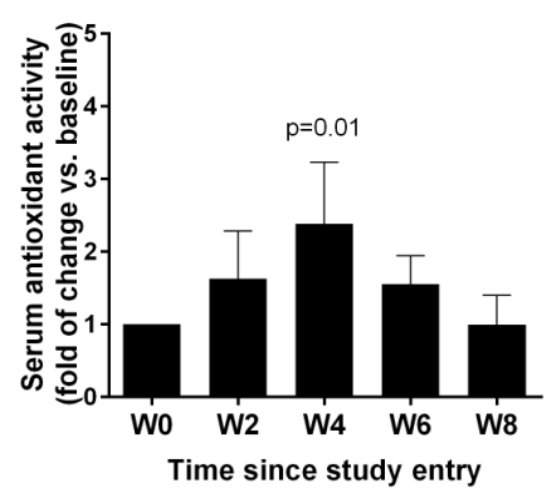

C
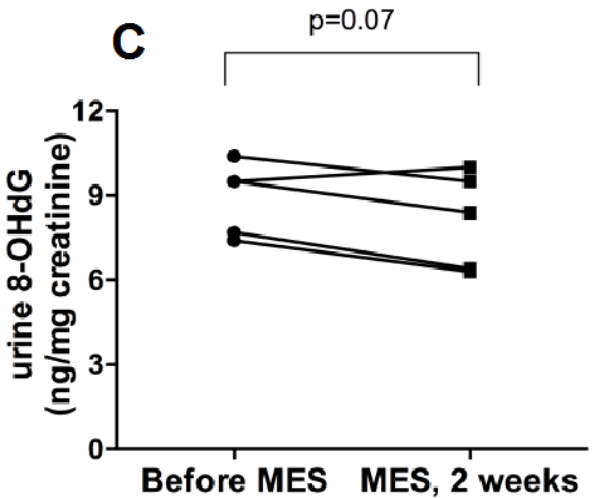

Figure 1: Effects of MSE on plasma oxidative stress parameters. (A) The plasma antioxidant capacity at baseline and two and four weeks after MES consumption administration of MSE. (B) Plasma carbonyl protein levels at baseline and at the indicated time (weeks). The reported fold changes in A and B are presented as means \pm SD of the values from five individuals measured at the indicated time points. (C) Urinary 8-OHdG levels in five individuals at baseline and at week two of the study.
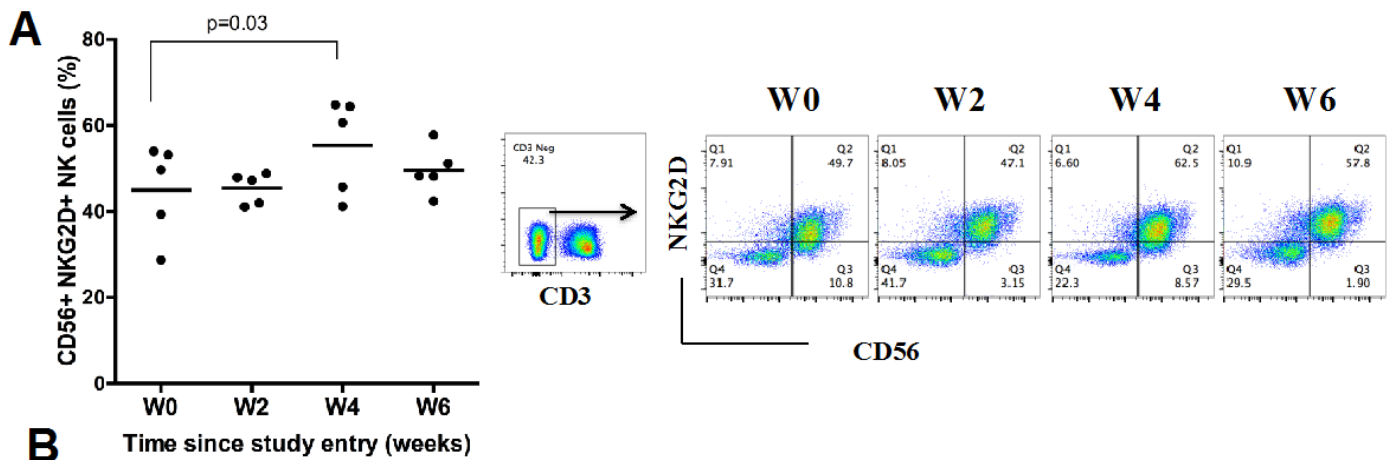

B Time since study entry (weeks)
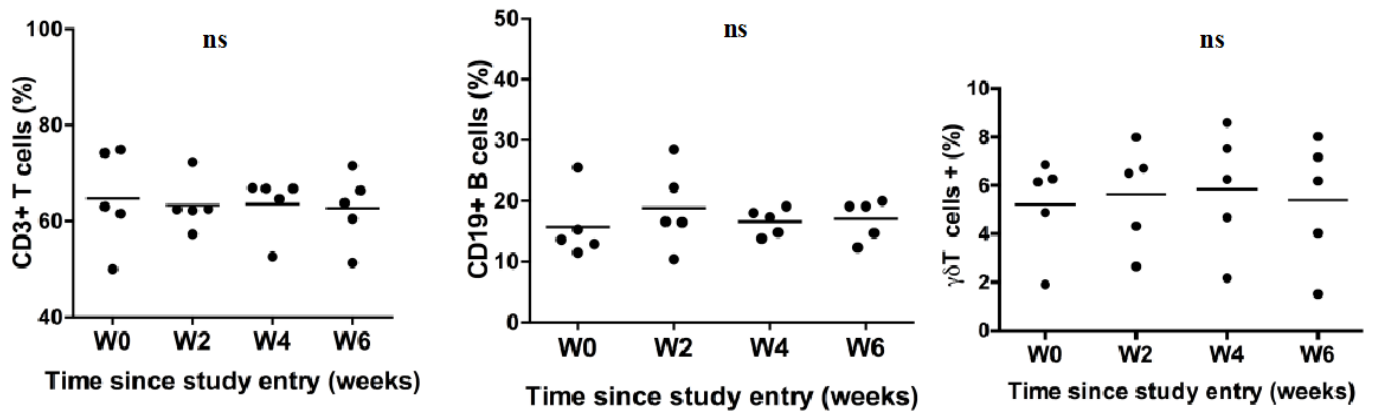

Figure 2: Effects of stilbene derivatives from MSE on circulating immune cells. (A) PBMCs from blood samples of the five individuals collected at baseline (W0) or at the indicated time (weeks) and the percentage of $\mathrm{CD}^{-}, \mathrm{CD} 56^{+} \mathrm{NKG}_{2} \mathrm{D}^{+} \mathrm{NK}$ cells (A), $\mathrm{CD}^{+} \mathrm{T}$ cells (B), CD19+ $\mathrm{B}$ cells (C) and and $\gamma \delta^{+} \mathrm{T}$ cells (D) were assessed by flow cytometry. The figures indicate the mean $\pm \mathrm{SD}$. In figure A, the summarized data from the five individuals in shown in the left panel and one representative result of one individual is shown in the right panel. 

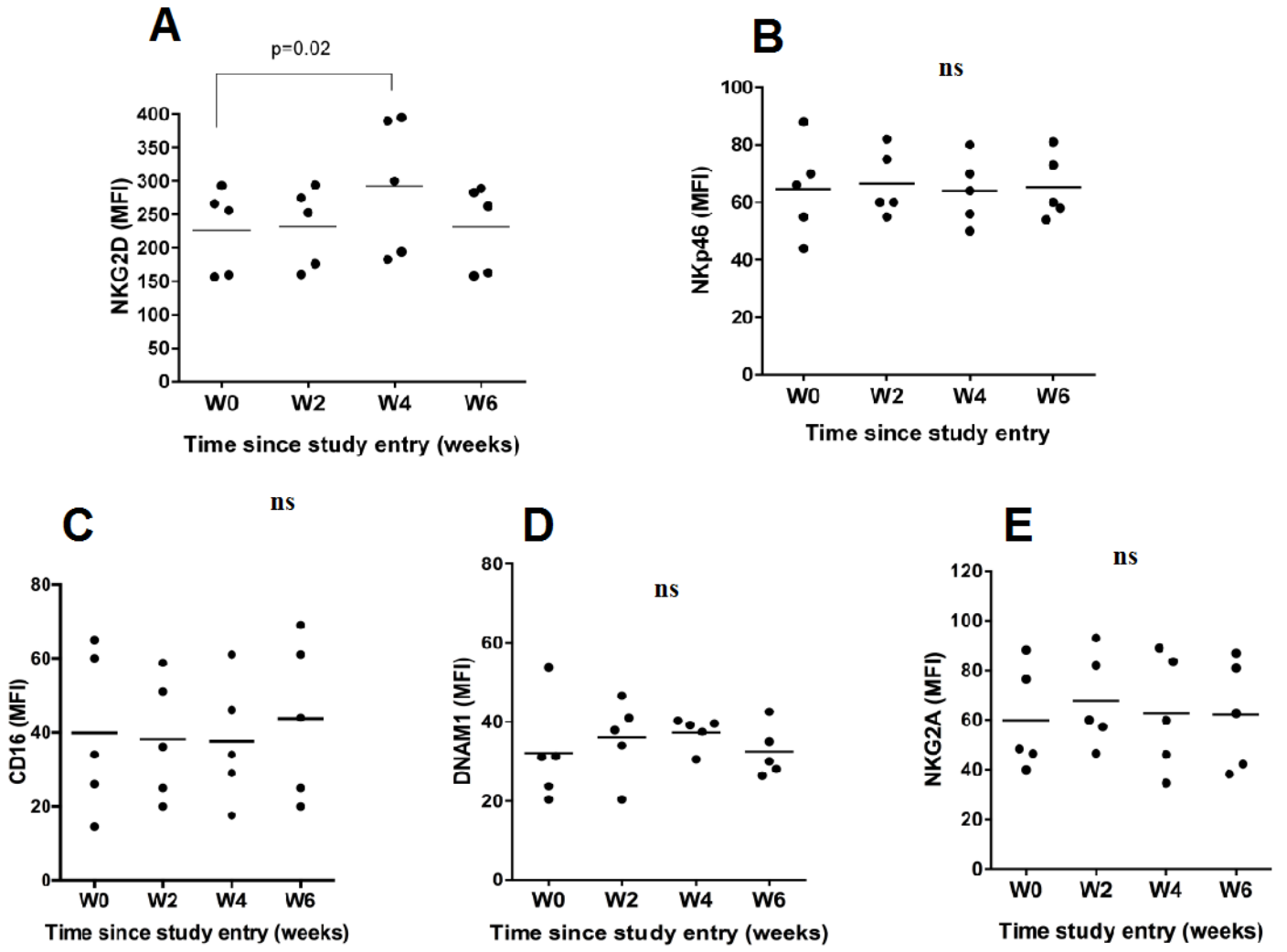

Figure 3: Expression of various receptor proteins on the surface of NK cells before and after MES intake. PBMC of five healthy individuals collected at baseline or at the indicated time

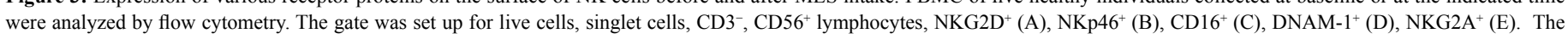
data represent the mean receptor MFI $\pm \mathrm{SD}$.

higher than at baseline. The Treg cell percentages returned to baseline levels by week 6 (Figure 4A).

To gain further insight into the biological effects of MES on immune cells, we first tested the in vitro proliferation of Treg cells from anti-CD3/CD28 and IL-2/IL-15 stimulated PBMCs derived from healthy individuals in the presence of various concentrations of MES. Under these culture conditions, the proportion of Treg cells (CD3+, $\left.\mathrm{CD} 25^{+}, \mathrm{CD}^{+}, \mathrm{CD} 127^{\text {neg/low }}\right)$ expanded from $4 \%$ to $32 \%$ in medium without MES and up to $42 \%$ in culture medium containing $1 \mu \mathrm{g} / \mathrm{ml}$ of MES (Figure4B).

To elucidate which component of MES was responsible for the outgrowth of circulating Treg cells, we next cultured PBMCs in the presence of either pure resveratrol $(2,5$ and $20 \mu \mathrm{M})$ or pure gnetin $C$ $(2,5$ and $20 \mu \mathrm{M})$. As shown in Figure $4 \mathrm{C}$, both resveratrol and gnetin $\mathrm{C}$ stimulated the proliferation of circulating Treg cells at doses of 2 and $5 \mu \mathrm{M}$. These effects were more apparent in gnetin C-treated cells. Notably, both compounds at doses of $20 \mu \mathrm{M}$ or higher significantly impaired the cell viability.

\section{MES inhibits inflammatory cytokine release from immune cells}

We next examined the expression of key inflammatory cytokines, including IFN- $\gamma$, TNF- $\alpha$ and GZMB, in the supernatants of PBMCs cultured with or without MES. In a dose-dependent manner, MES inhibited the spontaneous release of GZMB from cultured PBMCs (Figure 5A) and partially inhibited the release of IFN- $\gamma$ (Figure 5B) and TNF- $\alpha$ (Figure 5C) from IL-2 stimulated PBMCs. Notably, MES strongly attenuated IFN- $\gamma$ (Figure 5D), TNF- $\alpha$ (Figure 5E) and GZMB (Figure 5F) release from PHA activated PBMCs, indicating that MES may have anti-inflammatory potential. Because soluble GZMB is easily detectable in human plasma $[16,17]$, and the plasma levels of GZMB have been linked to pro-inflammatory conditions [16-19], we next assessed the GZMB levels in the plasma samples from the 5 individuals participating in this study. At two weeks after MES consumption the plasma levels of GZMB were similar to those of the baseline samples; however, by four weeks after MES consumption the GZMB levels were nearly undetectable. The plasma GZMB levels remained lower than baseline values at week six after starting MES consumption, however, at week eight and thereafter the GZMB levels returned to the baseline levels (Figure 5G).

\section{Discussion}

Numerous dietary derived phytochemicals have been reported to possess several health promoting properties, including cancer chemopreventive potential $[9,20]$. As a result, many of them are broadly consumed as phytonutrients and supplements [21]. In this study, we describe the effects of repeated administration of MES in healthy individuals, with a particular emphasis on documenting the changes on circulating immune cells and on plasma markers of oxidative stress as a result of the administration of this compound. MES derived stilbenes, at $320 \mathrm{mg}$ given daily for 28 consecutive days, was well tolerated and resulted in relevant biological effects that may have health promoting potential.

Reactive oxygen species (ROS), including hydrogen peroxide, superoxide anion and singlet oxygen, are highly reactive molecules 
A
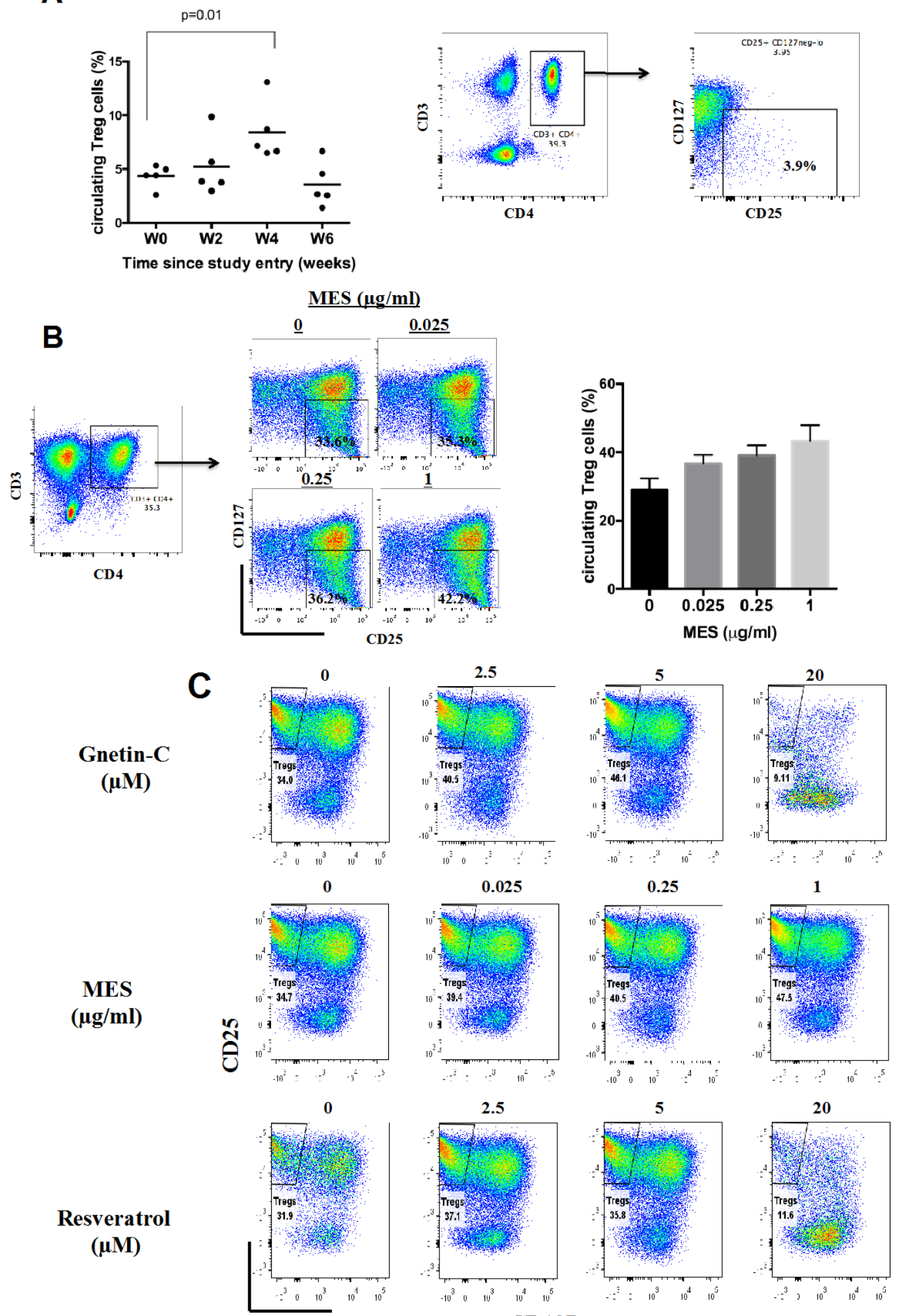

0.025

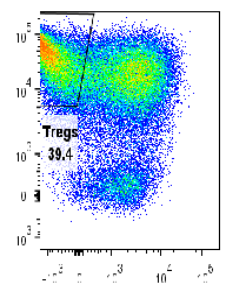

2.5

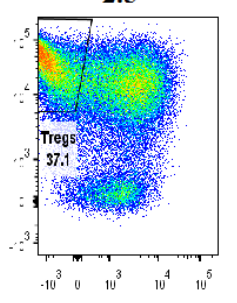

0.25

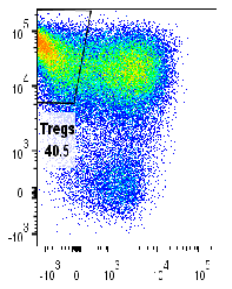

5

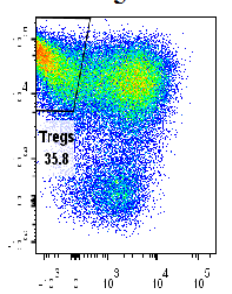

1

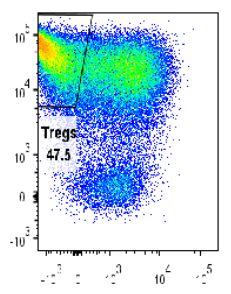

20

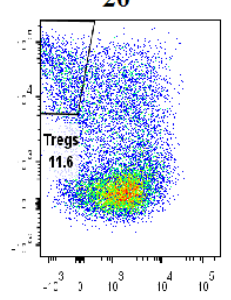

CD127

Figure 4: Effects of stilbene derivatives from MSE on the proliferation of circulating Treg cells (A) PBMCs from blood samples of the five individuals collected at baseline (W0) or at the indicated time (weeks) were analyzed by flow cytometry. The figure indicates the mean Treg cells \pm SD. (B) PBMCs derived from three healthy individuals were cultured for 4 days in complete medium supplemented with IL-15 and anti CD3/CD28 beads and with the indicated concentrations of MES. The cells were harvested and the percentage of circulating Treg cells was assessed by flow cytometry. The summarized data from the five individuals in shown in the left panel and one representative result of one individual is shown in the right panel. (C) PBMCs from three healthy individuals were cultured for 4 days in the presence of the indicated concentrations of MES, pure Gnetin C or pure trans-resveratrol. The percentage of circulating Treg cells was assessed by flow cytometry. One representative result of three independent experiments is shown. 

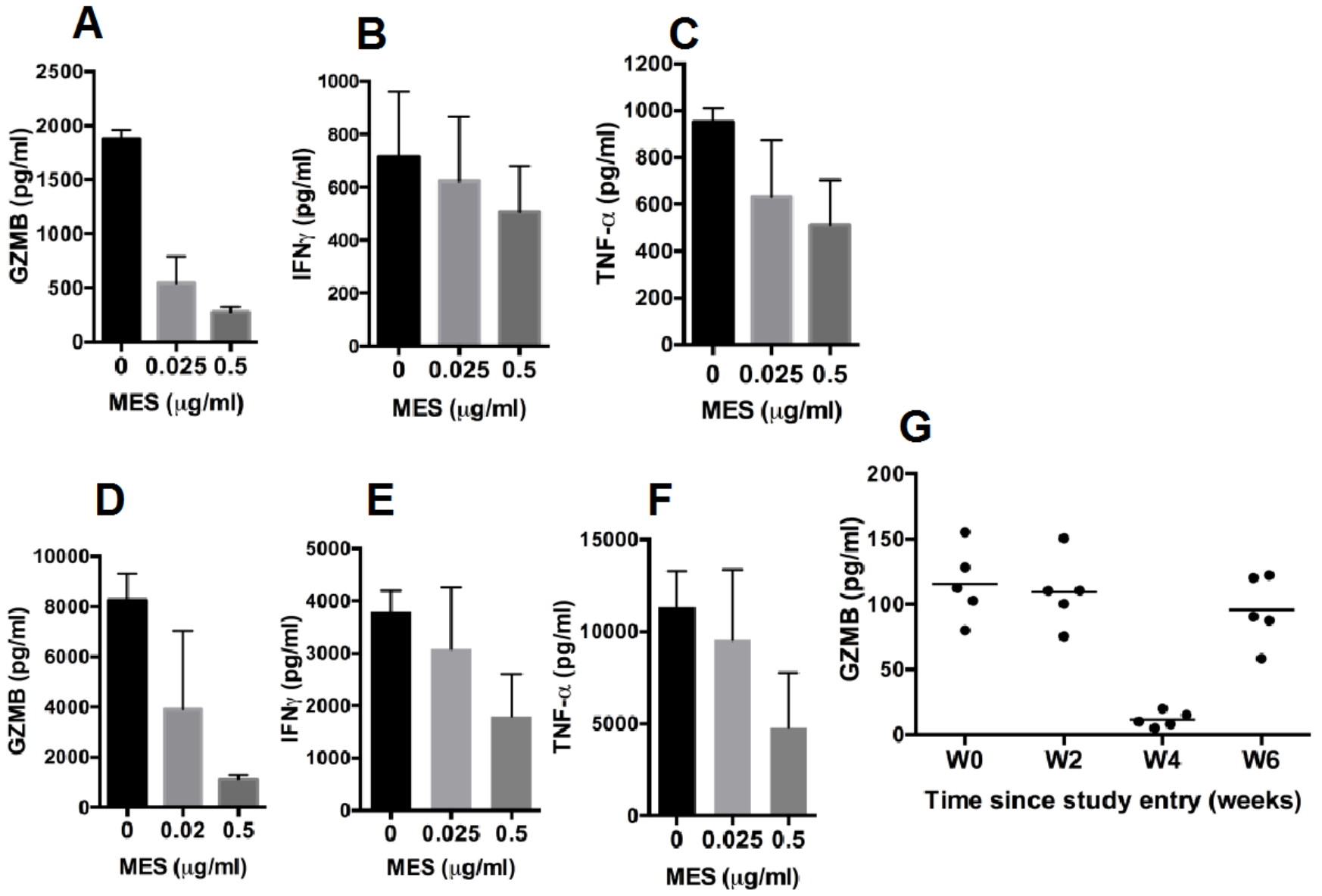

Figure 5: Effects of MES on inflammatory cytokine release from immune cells. PBMCs from three healthy individuals were cultured for 48 hours in the presence of the indicated concentrations of MES. The levels of GZMB (A), IFN- $\gamma(\mathrm{B})$ and TNF- $\alpha(\mathrm{C})$ in the culture supernatants were assessed by an ELISA assay. The data represent the mean analyte concentration \pm SD. PBMCs isolated from three healthy individuals were stimulated with PHA for 24 hours and then cultured for other 48 hoursin the presence of the indicated concentrations of MES. The levels of GZMB (D), IFN- $\gamma($ E) and TNF- $\alpha$ (F) in the culture supernatants were assessed by an ELISA. The data represent the mean analyte concentration \pm SD. (G) Plasma levels of GZMB as assessed by an ELISA, in samples from five individuals collected at baseline or at the indicated time. The data represent the mean GZMB concentration \pm SD.

that are continually produced during normal mitochondrial oxidative metabolism as well as in cellular response to exogenous insults, such as inflammation and microbial invasion [22,23]. Oxidative stress, which results from the imbalance of excess ROS production over the capability of the cells to mount an effective antioxidant response, has been implicated in the damage to macromolecules including DNA, lipids and proteins [22]. Oxidative stress has been proposed as one of the underlying molecular mechanisms of aging [24]. Many studies have shown that ROS play an important role in the development and progression of many human disorders, including atherosclerosis, inflammation, diabetes and cancer [22,23,25]. Our finding that MES enhanced the antioxidant capacity of the plasma in all the individuals participating in this study suggests that MES may contribute to preventing or ameliorating disorders associated with oxidative stress. In addition, our findings that MES intake decreased the carbonyl proteins levels in the plasma may support this assumption since protein carbonyl levels are the most frequently used biomarker of protein oxidation and their accumulation has been directly linked to an increased risk of cancer [26]. In fact, increased levels of protein carbonyl groups have been reported in samples derived from patients with several cancers, including bladder cancer [27], breast cancer [28], and Hodgkin's lymphoma [29]. Furthermore, in this study the plasma levels of 8 -OHdG decreased as a result of the consumption of MES. 8-OHdG, which is an oxidized derivative of deoxyguanosine, constitutes one of the major products of DNA oxidation. High levels of 8-OHdG have been causally associated with the risk of several cancers $[13,30]$. Therefore, our findings that MES decrease the circulating levels of $8-\mathrm{OHdG}$ and carbonylated plasma proteins can be interpreted as a potential mechanism by which this mixture of stilbenoids may exert cancer chemopreventive effects in humans. Further studies should establish whether MES, when given for periods exceeding 28 days, can persistently decrease the plasma levels of 8-OHdG and carbonyl proteins. In addition, testing these effects in individuals with increased levels of carbonylated proteins, such as heavy smokers or individuals with metabolic syndrome, will provide important information.

The concept of immunosurveillance to tumors implies that malignant cells arise continuously in the body and that immune cells seek out and eradicate these transformed cells before they are clinically manifested [31]. In this regard NK cells, which are effector lymphocytes of the innate immune system capable of spontaneously killing targets cells without prior recognition [32], have been suggested to play a crucial role in immunosurveillance. The role of NK cells in tumor surveillance is supported by epidemiological and correlation studies. For instance, a high NK cell-mediated cytotoxicity correlates 
with a decreased risk for cancer[33] and a high number of tumorinfiltrating NK cells has been associated with a better prognosis in cancer [34]. Furthermore, circulating NK cells express NKG2D, which is a stimulatory receptor whose role in tumor surveillance has been convincingly documented [35]. NKG2D recognizes and facilitate the killing of target cells expressing stress-induced specific ligands that are poorly expressed by normal cells but are frequently upregulated in transforming cells $[10,36]$. In this study, we found that MES consistently enhanced the expression of NKG2D receptor in circulating NK cells. In previous studies, culturing human NK cells in the presence of trans-resveratrol, which is one of the components of MES, was reported to upregulate NKG2D [10]. The present study provides in vivo evidence that confirms those previous reports and substantiates the immunomodulatory potential of MES in humans. According to these insights, we speculate that the findings of this study suggest that MES may have chemopreventive potential.

Our finding that MES intake is associated with a significant decrease in the plasma levels of GZMB is consistent with the notion that MES possess anti-inflammatory properties. GZMB has been largely associated with an intrinsic pro-apoptotic function since this protease, together with perforin, is the main constituent of cytoplasmic granules found in cytotoxic T lymphocytes (CTLs) and NK cells [37]. GZMB release from cytotoxic granules constitutes one of the main mechanisms by which these immune cells eliminate target cells [37]; however, in recent years, a non-cytotoxic or extracellular role of GZMB has emerged since the expression of this protease has been reported in nonimmune cells, such as smooth muscle cells, keratinocytes, and chondrocytes [38]. Because circulating GZMB remains entirely functional and elevated levels of circulating extracellular GZMB have been reported in association with various inflammatory conditions [16-18,39], it has been proposed that extracellular GZMB is an important contributor in the pathogenesis of certain chronic inflammatory diseases, reviewed by [37,38].

Regulatory $\mathrm{T}$ cells comprise a population of suppressor $\mathrm{T}$ cells that modulate tolerance to self-antigens and maintain immune homeostasis [40,41]. Although the characteristic surface markers of human Tregs remain under discussion, phenotypically they have been defined to be $\mathrm{CD}^{+}, \mathrm{CD}^{+} \mathrm{CD} 25$, and $\mathrm{CD} 127^{\text {low/neg }} \mathrm{T}$ cells [38]. At the transcriptional level, Treg cells are known to express the forkhead and winged-helix family of transcription factors protein, forkhead box P3 (FOXP3) [38]. Treg cells have been implicated in the pathogenesis of several autoimmune diseases in which a disturbed balance between pro-inflammatory and Treg cells leads to the breakdown of selftolerance. A reduced number of circulating $\mathrm{CD} 4^{+} \mathrm{CD} 25^{\text {hi }} \mathrm{T}$ cells has been reported in patients with several autoimmune diseases, including juvenile idiopathic arthritis, autoimmune liver disease, systemic lupus erythematosus and others [42]. Our findings that MES promotes the proliferation of Treg cells in vitro and that MES consumption correlated with an increased percentage of circulating Treg cells suggest that this compound may have therapeutic potential in certain autoimmune diseases. Although highly promising, it is unknown if the effects of MES in healthy individuals can be extrapolated to patients with autoimmune diseases since it has been documented that the reduced number of Treg cells in patients with autoimmune diseases is caused by the impaired proliferation of circulating $\mathrm{CD} 4^{+} \mathrm{CD} 25^{\text {hi }} \mathrm{T}$ cells [41]. Therefore, it is unknown whether a putative Treg cell promoting effect of stilbene derivatives from MES is able to overcome such a defective proliferation of Treg cells in those disorders.

There are some limitations associated with this study. The study included a small number of subjects and lacked a control or placebo group. Furthermore, it is difficult to determine whether the biological effects observed were exerted by resveratrol, gnetin $\mathrm{C}$, their metabolites, or by other components of MES or the combination thereof. Similar clinical studies have been previously performed to investigate the chemopreventive potential of other phytochemicals and it has been shown that such an exploratory approach can provide valid results not only to substantiate the biological relevance of phytochemicals, but also to reveal clues for designing larger clinical trials $[43,44]$. In addition, our in vitro studies, which confirm the biological effects of MES on immune cells, further substantiate the relevance of the findings herein reported. Future studies with a greater accumulation of participants and longer exposure to MES are necessary to confirm these observations and elucidate the mechanisms involved.

\section{Competing interests}

The authors declare that there is no conflict of interest regarding the publication of this paper.

\section{Authors' contributions}

JLE and AT conceived and designed the studies; JLE, DTA, LQT and KY performed the experiments; JLE, AT, LQT and SN analyzed the data; JLE and AT wrote the manuscript.

\section{Funding}

This study was supported by grants from the Ministry of Health, Labour and Welfare of Japan and the Ministry of Education, Culture, Sports and Technology of Japan. The grant sources played no role in the study design, data collection and analysis, decision to publish or preparation of the manuscript.

\section{References}

1. Kato E, Tokunaga Y, Sakan F (2009) Stilbenoids isolated from the seeds of Melinjo (Gnetum gnemon L.) and their biological activity. J Agric Food Chem 57: 2544-9. [Crossref]

2. Kunimasa K, Ohta T, Tani H, Kato E, Eguchi R, et al. (2011) Resveratrol derivativerich melinjo (Gnetum gnemon L.) seed extract suppresses multiple angiogenesis-related endothelial cell functions and tumor angiogenesis. Mol Nutr Food Res 55: 1730-4. [Crossref]

3. Kato H, Samizo M, Kawabata R, Takano F, Ohta T (2011) Stilbenoids from the melinjo (Gnetum gnemon L.) fruit modulate cytokine production in murine Peyer's patch cells ex vivo. Planta Med 77:1027-34. [Crossref]

4. Tani H, Hikami S, Iizuna S, Yoshimatsu M, Asama T, et al. (2014) Pharmacokinetics and safety of resveratrol derivatives in humans after oral administration of melinjo (Gnetum gnemon L.) seed extract powder. J Agric Food Chem 62: 1999-2007. [Crossref]

5. Konno H, Kanai Y, Katagiri M, Watanabe T, Mori A, et al. (2013) Melinjo (Gnetum gnemon L.) Seed Extract Decreases Serum Uric Acid Levels in Nonobese Japanese Males: A Randomized Controlled Study. Evid Based Complement Alternat Med : 589169. [Crossref]

6. Tatefuji T, Yanagihara M, Fukushima S, Hashimoto K (2014) Safety assessment of melinjo (Gnetum gnemon L.) seed extract: acute and subchronic toxicity studies. Food Chem Toxicol 67: 230-5. [Crossref]

7. Rascón B, Hubbard BP, Sinclair DA, Amdam GV (2012) The lifespan extension effects of resveratrol are conserved in the honey bee and may be driven by a mechanism related to caloric restriction. Aging (Albany NY) 4: 499-508. [Crossref]

8. Baur JA, Sinclair DA (2006) Therapeutic potential of resveratrol: the in vivo evidence. Nat Rev Drug Discov 5: 493-506. [Crossref]

9. Espinoza JL, Takami A, Trung LQ, Kato S, Nakao S (2012) Resveratrol Prevents EBV Transformation and Inhibits the Outgrowth of EBV-Immortalized Human B Cells. PLoS One 7: e51306. [Crossref]

10. Luis Espinoza J, Takami A, Trung LQ, Nakao S (2013) Ataxia-telangiectasia mutated 
kinase-mediated upregulation of NKG2D ligands on leukemia cells by resveratrol results in enhanced natural killer cell susceptibility. Cancer Sci 104: 657-62. [Crossref]

11. 4.0 CTCfAECV. Accessed 2013 Apr 15. 2010

12. Muzzio M, Huang Z, Hu SC, Johnson WD, McCormick DL, et al. (2012) Determination of resveratrol and its sulfate and glucuronide metabolites in plasma by LC-MS/MS and their pharmacokinetics in dogs. J Pharm Biomed Anal 59: 201-8. [Crossref]

13. Valavanidis A, Vlachogianni T, Fiotakis C (2009) 8-hydroxy-2' -deoxyguanosine (8-OHdG): A critical biomarker of oxidative stress and carcinogenesis. J Environ Sci Health C Environ Carcinog Ecotoxicol Rev 27:120-39. [Crossref]

14. Yao J, Wei C, Wang JY, Zhang R, Li YX, et al. (2015) Effect of resveratrol on Treg/ Th17 signaling and ulcerative colitis treatment in mice. World $J$ Gastroenterol 21: 6572-81. [Crossref]

15. Hein F, Massin F, Cravoisy-Popovic A, Barraud D, Levy B, et al. (2010) The relationship between $\mathrm{CD} 4+\mathrm{CD} 25+\mathrm{CD} 127$ - regulatory $\mathrm{T}$ cells and inflammatory response and outcome during shock states. Crit Care 14: R19. [Crossref]

16. El Mesallamy HO, Hamdy NM, Mostafa DM, Amin AI (2014) The serine protease granzyme $\mathrm{B}$ as an inflammatory marker, in relation to the insulin receptor cleavage in human obesity and type 2 diabetes mellitus. J Interferon Cytokine Res 34:179-86. [Crossref]

17. Skjelland M, Michelsen AE, Krohg-Sørensen K, Tennøe B, Dahl A, et al. ( 2007) Plasma levels of granzyme B are increased in patients with lipid-rich carotid plaques as determined by echogenicity. Atherosclerosis 195: e142-6. [Crossref]

18. Tschopp CM, Spiegl N, Didichenko S, Lutmann W, Julius P, Virchow JC, et al. (2006) Granzyme B, a novel mediator of allergic inflammation: its induction and release in blood basophils and human asthma. Blood 108: 2290-9. [Crossref]

19. Boivin WA, Cooper DM, Hiebert PR, Granville DJ (2009) Intracellular versus extracellular granzyme B in immunity and disease: challenging the dogma. Lab Invest 89: 1195-220. [Crossref]

20. Surh YJ (2003) Cancer chemoprevention with dietary phytochemicals. Nat Rev Cancer 3: 768-80. [Crossref]

21. Scott E, Steward WP, Gescher AJ, Brown K (2012) Resveratrol in human cancer chemoprevention--choosing the 'right' dose. Mol Nutr Food Res 56: 7-13. [Crossref]

22. Sullivan LB, Chandel NS (2014) Mitochondrial reactive oxygen species and cancer Cancer Metab 2: 17. [Crossref]

23. Jones DP (2015) Redox theory of aging. Redox Biol 5: 71-9. [Crossref]

24. Ralser M, Lehrach H (2009) Building a new bridge between metabolism, free radicals and longevity. Aging (Albany NY)1: 836-8. [Crossref]

25. Richardson C, Yan S, Vestal CG (2015) Oxidative stress, bone marrow failure, and genome instability in hematopoietic stem cells. Int J Mol Sci 16: 2366-85. [Crossref]

26. Madian AG, Regnier FE (2010) Profiling carbonylated proteins in human plasma. $J$ Proteome Res 9:1330-43. [Crossref]

27. Yilmaz IA, Akçay T, Cakatay U, Telci A, Ataus S, et al. (2003) Relation between bladder cancer and protein oxidation. Int Urol Nephrol 35: 345-50. [Crossref]

28. Rossner P, Terry MB, Gammon MD, Agrawal M, Zhang FF, et al. (2007) Plasma protein carbonyl levels and breast cancer risk. J Cell Mol Med 11: 1138-48. [Crossref]
29. Morabito F, Cristani M, Saija A, Stelitano C, Callea V, et al. Lipid peroxidation and protein oxidation in patients affected by Hodgkin's lymphoma. Mediators Inflamm 13 381-3. [Crossref]

30. Wu LL, Chiou CC, Chang PY, Wu JT (2004) Urinary 8-OHdG: a marker of oxidative stress to DNA and a risk factor for cancer, atherosclerosis and diabetics. Clin Chim Acta 339:1-9. [Crossref]

31. Kim R, Emi M, Tanabe K (2007) Cancer immunoediting from immune surveillance to immune escape. Immunol 121:1-14. [Crossref]

32. Sinkovics JG, Horvath JC (2005) Human natural killer cells: a comprehensive review. Int J Oncol 27: 5-47. [Crossref]

33. Imai K, Matsuyama S, Miyake S, Suga K, Nakachi K (2000) Natural cytotoxic activity of peripheral-blood lymphocytes and cancer incidence: an 11-year follow-up study of a general population. Lancet 356:1795-9. [Crossref]

34. Ishigami S, Natsugoe S, Tokuda K, Nakajo A, Xiangming C, et al. (2000) Clinical impact of intratumoral natural killer cell and dendritic cell infiltration in gastric cancer. Cancer Lett 159:103-8. [Crossref]

35. Guerra N, Tan Y, Joncker N, Choy A, Gallardo F, et al. NKG2D-deficient mice are defective in tumor surveillance in models of spontaneous malignancy. Immunity 28 : 571-80. [Crossref]

36. López-Larrea C, Suárez-Alvarez B, López-Soto A, López-Vázquez A, Gonzalez S (2008) The NKG2D receptor: sensing stressed cells. Trends Mol Med 14:179-89. [Crossref]

37. Cullen SP, Brunet M, Martin SJ (2010) Granzymes in cancer and immunity. Cell Death Differ 17: 616-23.[Crossref]

38. Boivin WA, Cooper DM, Hiebert PR, Granville DJ (2009) Intracellular versus extracellular granzyme B in immunity and disease: challenging the dogma. Lab Invest 89: 1195-220. [Crossref]

39. Goldbach-Mansky R, Suson S, Wesley R, Hack CE, El-Gabalawy HS, et al. (2005) Raised granzyme $\mathrm{B}$ levels are associated with erosions in patients with early rheumatoid factor positive rheumatoid arthritis. Ann Rheum Dis 64: 715-21. [Crossref]

40. Brusko TM, Putnam AL, Bluestone JA (2008) Human regulatory T cells: role in autoimmune disease and therapeutic opportunities. Immunol Rev 223: 371-90. [Crossref]

41. Carbone F, De Rosa V, Carrieri PB, Montella S, Bruzzese D, et al. (2014) Regulatory $\mathrm{T}$ cell proliferative potential is impaired in human autoimmune disease. Nat Med 20: 69-74. [Crossref]

42. Dejaco C, Duftner C, Grubeck-Loebenstein B, Schirmer M (2006) Imbalance of regulatory T cells in human autoimmune diseases. Immunol 117: 289-300. [Crossref]

43. Cruz-Correa M, Shoskes DA, Sanchez P, Zhao R, Hylind LM, et al. (2006) Combination treatment with curcumin and quercetin of adenomas in familial adenomatous polyposis. Clin Gastroenterol Hepatol 4:1035-8. [Crossref]

44. Brown VA, Patel KR, Viskaduraki M, Crowell JA, Perloff M, et al. (2010) Repeat dose study of the cancer chemopreventive agent resveratrol in healthy volunteers: safety, pharmacokinetics, and effect on the insulin-like growth factor axis. Cancer Res 70 : 9003-11. [Crossref]

Copyright: (C2015 Luis Espinoza J. This is an open-access article distributed under the terms of the Creative Commons Attribution License, which permits unrestricted use, distribution, and reproduction in any medium, provided the original author and source are credited. 